Part of Journal of Research of the National Bureau of Standards, Volume 28, February 1942

\title{
CALCULATION OF PROTEIN-ANION AFFINITY CON- STANTS FROM ACID TITRATION DATA
}

\author{
By Jacinto Steinhardt ${ }^{1}$
}

\section{ABSTRACT}

It has been shown earlier that the titration curves of wool and other proteins obtained with different strong acids differ widely in position with respect to the $\mathrm{pH}$ coordinate. By assuming that these differences were due to combination of the protein with anions as well as with hydrogen ions, it was possible to calculate from the $\mathrm{pH}$ of the midpoint of each curve numerical values of the affinity of each anion for wool. In the present paper modifications of the equations for calculating anion affinity are described. It is shown that the new equations describe the titration curves as a whole instead of merely the positions of their midpoints. The new forms are also shown to describe the effects of the presence of salts on the titration curves at least as adequately as did the earlier ones.

\section{CONTENTS}

1. Introduction__._.

II. The calculation of affinity with the modified equations

III. Experimental justification of the modified equations _...

1. Data obtained in the absence of salt

2. Data obtained in the presence of salt

I V. References

\section{INTRODUCTION}

It has been shown previously that wool combines reversibly with different acids to very different extents $[2,6] .^{2}$ The titration curves obtained with each acid (amounts combined plotted against $\mathrm{pH}$ ), while essentially congruent with one another, differ widely in position with respect to the $\mathrm{pH}$ coordinate. The existence of these differences, which have also been found with the soluble protein, egg albumin, distinguishes the reaction of proteins with acids from other acid-base equilibria, and indicates that more is involved than a proton exchange. Earlier experiments concerned with the effect of potassium chloride on the titration curves obtained with hydrochloric acid suggested an interpretation in terms of combination of the protein with anions as well as with hydrogen ions [3]. A simple extension of the earlier

\footnotetext{
1 Research Associate at the National Bureau of Standards, representing the Textile Foundation.
}

- Figures in brackets indicate the literature references at the end of this paper. 
analysis was therefore employed to calculate numerical values of the several anion-protein dissociation constants (values of $K_{\mathrm{A}}{ }^{\prime}$ corresponding to titration with each acid, which were shown to differ from one another many thousandfold. The equations employed and the constants so calculated were used in analyzing the effects on the curves of the presence of salts of some of the acids, and in calculating the heats of dissociation from the protein of a number of the anions involved.

The present paper describes a slight modification in the method of calculation, which is made in order to extend the range of usefulness of the previously formulated equations. With this modification, the equations represent quite closely the course of the entire curves and not merely, as before, the relative positions of their respective midpoints.

\section{THE CALCULATION OF AFFINITY WITH THE MODIFIED EQUATIONS}

The equations previously used to represent the dependence of the amounts combined on the hydrogen ion and anion activities $\left(a_{\mathrm{н}}\right.$ and $a_{\Lambda}$ ) were derived by considering the following postulated equilibria, each governed by its corresponding constant:

$\begin{array}{ll}K_{\mathrm{H}}{ }^{\prime} & \mathrm{WHA} \rightleftharpoons \mathrm{WA}^{-}+\mathrm{H}^{+} \\ K_{\mathrm{A}}{ }^{\prime} & \mathrm{WA}^{-} \rightleftharpoons \mathrm{W}^{ \pm}+\mathrm{A}^{-} \\ K_{\mathrm{H}} & \mathrm{WH}^{+} \rightleftharpoons \mathrm{W}^{ \pm}+\mathrm{H}^{+} \\ K_{\mathrm{A}} & \mathrm{WHA} \rightleftharpoons \mathrm{WH}^{+}+\mathrm{A}^{-},\end{array}$

in which $W^{ \pm}, W H^{+}$, etc., represent ionic states of wool. The constants are not independent but are necessarily interrelated by the equation $K_{\mathrm{H}}{ }^{\prime} K_{\mathrm{A}}{ }^{\prime}=K_{\mathrm{H}} K_{\mathrm{A}}$.

Two different expressions for the amounts of acid combined in the absence of salt were obtained by combining these equilibria:

$$
\begin{aligned}
& \frac{\left[\mathrm{WHA}^{+}+\left[\mathrm{WH}^{+}\right]\right.}{[\mathrm{WHA}]+\left[\mathrm{WH}^{+}\right]+\left[\mathrm{WA}^{-}\right]+\left[\mathrm{W}^{+}\right]}=\frac{1}{1+\frac{K_{\mathrm{H}}}{a_{\mathrm{H}}}\left[\frac{a_{\mathrm{H}}+K_{\mathrm{A}}{ }^{\prime}}{a_{\mathrm{H}}+K_{\mathrm{A}}}\right]} \\
& {\left[\frac{\left[\mathrm{WHA}^{2}\right]+\left[\mathrm{WA}^{-}\right]}{\left[\mathrm{WHA}^{-}\left[\mathrm{WH}^{+}\right]+\left[\mathrm{WA}^{-}\right]+\left[\mathrm{W}^{ \pm}\right]\right.}=\frac{1}{1+\frac{K_{\mathrm{A}}}{a_{\mathrm{H}}}\left[\frac{a_{\mathrm{H}}+K_{\mathrm{H}}}{a_{\mathrm{H}}+K_{\mathrm{H}}{ }^{\prime}}\right]}\right. \text {. }}
\end{aligned}
$$

On the basis of the methods used earlier for measuring the amounts of acid combined with wool, eq 1 represents the fraction of the wool fully combined with acid when the parameters are such that $\left[\mathrm{WH}^{+}\right]>$ $\left[\mathrm{WA}^{-}\right]$. Equation 2 represents this fraction in the opposite case, $\left[\mathrm{WA}^{-}\right]>\left[\mathrm{WH}^{+}\right]$. Because of this difference in the conditions of their applicability, eq 1 and 2 are referred to hereafter as the low-affinity and the high-affinity equations, respectively. $K_{\mathrm{A}}{ }^{\prime}$ may be obtained 
directly from $\boldsymbol{a}_{\mathrm{H}}$, the value of $a_{\mathrm{H}}$ at which half the maximum amount of acid is bound, by means of the relations:

$$
\begin{aligned}
& K_{\mathrm{A}}^{\prime}=\frac{\boldsymbol{a}_{\mathrm{H}}\left(\boldsymbol{a}_{\mathrm{H}}-K_{\mathrm{H}}{ }^{\prime}\right)}{K_{\mathrm{H}}^{\prime}} \times \frac{K_{\mathrm{H}}}{K_{\mathrm{H}}-\boldsymbol{a}_{\mathrm{H}}} \\
& K_{\mathrm{A}}^{\prime}=\frac{\boldsymbol{a}_{\mathrm{H}}\left(\boldsymbol{a}_{\mathrm{H}}+K_{\mathrm{H}}{ }^{\prime}\right)}{K_{\mathrm{H}}^{\prime}} \times \frac{K_{\mathrm{H}}}{K_{\mathrm{H}}+\boldsymbol{a}_{\mathrm{H}}},
\end{aligned}
$$

which apply respectively to the same conditions as eq 1 and 2 .

It is evident that the simple equations used to calculate ${K_{\mathrm{A}}}^{\prime}$ were derived from the law of mass action by treating the dissociation of each ion from the protein as if each dissociation occurred in a different molecule (i. e., as if the protein molecules were strictly monovalent). Formulations based upon this obviously unreal assumption must fail to describe accurately the dependence of the amounts of acid (or of hydrogen ion) combined (i. e., undissociated) as a function of $\mathrm{pH}$, regardless of their usefulness in predicting the dependence of the position or shape of the titration curve with a given acid relative to other titration curves, or its dependence on other variables, such as the anion concentration. When sets of dissociating groups are present in a single molecule instead of being uniformly distributed among different molecules, interaction between the members of each set is bound to result - that is, the state of ionization of the molecule as a whole determines its charge, and must have an influence on the tendency of any one group to ionize. The formulation of an equation in terms of a single dissociation constant disregards that influence. However, it was pointed out previously $[2,3,5]$ that the oversimplified equations could be made to represent the entire course of the individual titration curves very closely if the concentration terms were permitted to enter into the equations as square roots. The constants $K_{\mathrm{H}^{\prime}}{ }^{\prime}, K_{\mathrm{A}}{ }^{\prime}$, etc., must then be changed for numerical consistency in the computation to the corresponding square roots $\left(K_{\mathrm{H}}{ }^{\prime}\right)^{3 / 2},\left(K_{\mathrm{A}}{ }^{\prime}\right)^{1 / 2}$, etc.), although the actual average values of the dissociation constants may be still given by the first powers [5, $\left.{ }^{11}\right]$. Equations of this type (in which, however, the only variable was the hydrogen-ion concentration) have been used by Kern [1] in describing titration data obtained with a number of compounds of high molecular weight. In the present work the anion concentration terms must also be changed to square roots, since it has already been demonstrated [3] that hydrogen-ion and anion terms affect the acid-combination function to approximately equal extents.

If, in order to gain the advantages described, all activity terms and constants are introduced as square roots, $\left(\left[\mathrm{WH}^{+}\right]=\frac{\left[\mathrm{W}^{ \pm}\right]\left[\mathrm{H}^{+}\right]^{1 / 2}}{K_{\mathrm{H}^{1 / 2}}}\right.$, etc. $)$ the foregoing equations become the following:

$$
\begin{aligned}
& \text { Fraction combined }=\frac{1}{1+\left(\frac{K_{\mathrm{H}}{ }^{\prime}}{a_{\mathrm{H}}}\right)^{1 / 2}\left[\frac{a_{\mathrm{H}}^{1 / 2}+\left(K_{\mathrm{A}}{ }^{\prime}\right)^{1 / 2}}{a_{\mathrm{H}}{ }^{1 / 2}+\left(K_{\mathrm{A}}\right)^{1 / 2}}\right]} \\
& \text { Fraction combined }=\frac{1}{1+\left(\frac{K_{\mathrm{A}}}{a_{\mathrm{H}}}\right)^{1 / 2}\left[\frac{a_{\mathrm{H}}^{1 / 2}+\left(K_{\mathrm{H}}\right)^{1 / 2}}{a_{\mathrm{H}}{ }^{1 / 2}+\left(K_{\mathrm{H}}{ }^{1 / 2}\right.}\right]}
\end{aligned}
$$


and $K_{\mathrm{A}}{ }^{\prime}$ should be calculated by the relations:

$$
\begin{aligned}
& \left(K_{\mathrm{A}}{ }^{\prime}\right)^{1 / 2}=\frac{\boldsymbol{a}_{\mathrm{H}}{ }^{1 / 2}\left[\boldsymbol{a}_{\mathrm{H}^{3 / 2}}-\left(K_{\mathrm{H}^{\prime}}\right)^{1 / 2}\right]}{\left(K_{\mathrm{H}}{ }^{\prime}\right)^{1 / 2}} \times \frac{k_{\mathrm{H}^{1 / 2}}}{K_{\mathrm{H}}{ }^{1 / 2}-\boldsymbol{a}_{\mathrm{H}^{1 / 2}}} \\
& \left(K_{\mathbf{A}}{ }^{\prime}\right)^{1 / 2}=\frac{\boldsymbol{a}_{\mathrm{H}^{1 / 2}}\left[\boldsymbol{a}_{\mathrm{H}^{3 / 2}}+\left(K_{\mathrm{H}^{\prime}}\right)^{1 / 2}\right]}{\left(K_{\mathrm{H}}{ }^{\prime}\right)^{1 / 2}} \times \frac{K_{\mathrm{H}}{ }^{1 / 2}}{K_{\mathrm{H}}{ }^{3 / 2}+\boldsymbol{a}_{\mathrm{H}^{1 / 2}}}
\end{aligned}
$$

It is apparent that the values of $K_{\mathrm{A}}{ }^{\prime}$ and $K_{\mathrm{H}}{ }^{\prime}$, calculated from the modified equation, will differ somewhat from those previously calculated from the equations which lack the empirical exponent. The extent of this difference is small, as is made evident elsewhere [7].

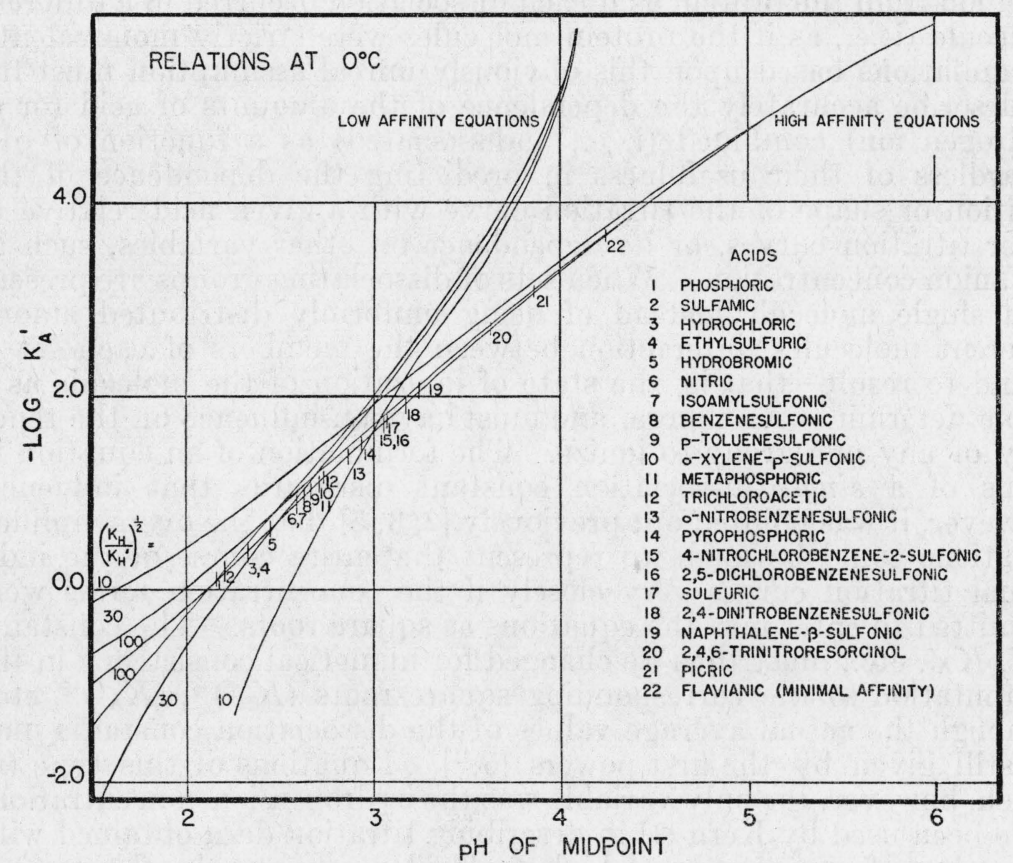

FIGURE 1.-Relation between the position of the acid titration curve with respect to $\mathrm{pH}$ and the affinity of the anion of the acid for protein.

Two sets of curves are shown, representing eq $3^{\prime}$ (low affinity) and $4^{\prime}$ (high affinity), respectively. The individual curves within each set were obtained by assuming three different ratios of $\left(K_{\mathrm{H}}\right)^{1 / 2}$ to $\left(K_{\mathrm{H}^{\prime}}\right)^{1 / 2}$. The point for 0 -phenolsulfonic acid, which has been omitted, would coincide with the point for $p$-toluenesulfonic acid.

In the earlier treatment $K_{\mathrm{H}}$, which cannot be evaluated directly, was eliminated by an approximation which further simplified eq $1^{\prime}$ and $2^{\prime}$. The simplified equations were represented graphically, and the values of $K_{\mathrm{A}}^{\prime}$ tabulated were obtained from the graph [2,6]. In the present paper, advantage is taken of the exact forms (eq $3^{\prime}$ and $4^{\prime}$ ) to appraise the effect of uncertainty as to the value of $K_{\mathrm{H}}$ on the values of $K_{\mathrm{A}}^{\prime}$ calculated. This has been done (fig. 1) by plotting both equations $3^{\prime}$ and $4^{\prime}$ for three different ratios of $\left(K_{\mathrm{H}} / K_{\mathrm{H}}^{\prime}\right)^{\frac{3}{2}}$. The values selected for this ratio, 10,30 , and 100 are greater than unity because of electrostatic considerations which have been discussed elsewhere $[2,6]$. It is apparent that for each equation the relation 
between affinity and midpoint $\mathrm{pH}$ becomes relatively independent of the ratio chosen if the affinity is high, but is increasingly dependent upon it as the anion affinity decreases. The highest ratio of the three represented has been adopted in further calculations because it leads to the results most compatible with the shapes of the individual titration curves, and with the effect of chlorides on the position of the hydrochloric acid titration curves previously described [3].

Fortunately, with the highest of these ratios it is practically immaterial whether eq $3^{\prime}$ or $4^{\prime}$ be used for the calculation of affinity in the case of the only anions (i. e., those with the lowest affinities) for which the choice between the two equations is not immediately apparent. In figure 1 the position of the midpoint of each of the titration curves at $0^{\circ} \mathrm{C}$ has been indicated by a short vertical line intercepting the curve which represents eq $4^{\prime}$ and a ratio of 100 . Since all the points indicated fall in a region for which the curve representing eq $4^{\prime}$ is lower than the curve representing eq $3^{\prime}$, it is obvious that with this ratio eq $4^{\prime}$ rather than eq $3^{\prime}$ must be used to calculate the affinity for wool of all of the anions represented. ${ }^{3}$ In another paper [7] values of $K_{\mathrm{A}}{ }^{\prime}$ for 33 different acids obtained by the use of eq $4^{\prime}$ are tabulated and compared with those previously given.

\section{EXPERIMENTAL JUSTIFICATION OF THE MODIFIED EQUATIONS}

\section{DATA OBTAINED IN THE ABSENCE OF SALT}

The accuracy with which the modified equation describes in detail individual titration curves is shown in figure 2. The curves in this figure represent the theoretical relations which are obtained when values of $K_{\mathbf{A}^{\prime}}$, shown in figure 1 for a number of acids selected to cover a wide range of affinity, and the value of $K_{\mathrm{H}}{ }^{\prime}$ at $0^{\circ} \mathrm{C}$ previously established [3,5] are inserted in eq 4 . The logarithmic ordinate has been chosen because it yields approximation to a linear relation to $\mathrm{pH}$ [3], and furnishes a more critical visual criterion of fit than a linear ordinate allows. Because of the exaggerated sensitivity of this form of function to experimental error when either very large or very small amounts of acid are combined, the data represented are limited to amounts combined between about 5 percent and 95 percent of the maximum. An additional reason for this restriction is the existence of an "excess" take-up of acid beyond 0.82 millimole per gram; it cannot be expected that a function based on this "maximum" will be entirely successful in representing data which approach this value. 0.03 millimole has been subtracted from all the amounts combined, in order to eliminate the estimated contribution of the histidine content of the fibers; the data are thus restricted to the results of back-titrating a single set of groups, the carboxyls.

The good agreement of the curves with the experimental data shows that practically the same values of $K_{\mathrm{A}}{ }^{\prime}$ as these calculated from the midpoint $\mathrm{pH}$ values of each of the titration curves would be obtained if points representing any other extent of combination had been consistently chosen, and used in conjunction with the appropriately modified eq $4^{\prime}$. This would not have been the case if the

${ }^{3}$ The $\mathrm{pH}$ at which eq $3^{\prime}$ and $4^{\prime}$ intersect for any given ratio of $\left(K_{\mathrm{H}} / K_{\mathrm{H}^{\prime}}\right)^{1 / 2}$, is the $\mathrm{pH}$ above which [WA-] is larger than [ $\left.\mathrm{WH}^{+}\right]$. By definition, eq $4^{\prime}$ applies when [ $\left.\mathrm{WA}^{-}\right]$is larger than $\left[\mathrm{WH}^{+}\right]$.

$435456-42-5$ 
integral power equation previously employed had been used. This ability of eq 4 to describe the titration curves in detail is essential to a treatment of more complicated systems, such as mixtures of acids

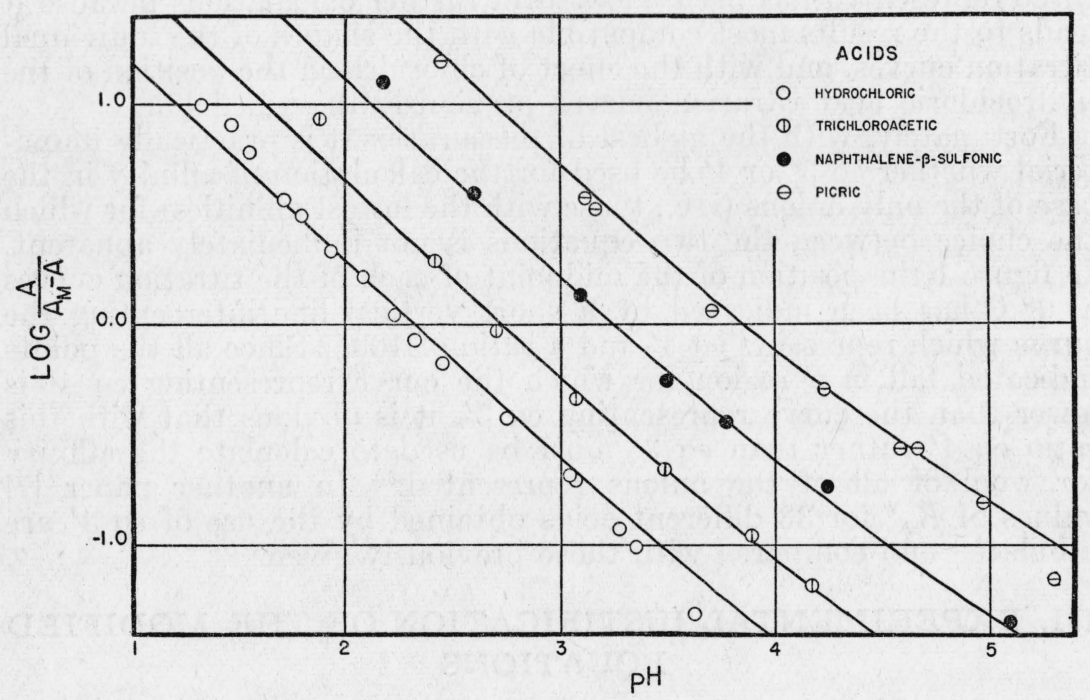

Figure 2.-The amounts of 4 different acids combined by wool as a function of $\mathrm{pH}$. The curves are theoretical (eq 4) and have been calculated for each acid by using the values of $K_{\star}$ given by eq $4^{\prime}$.

or acids and salts, since attention cannot then be confined to the points of half-maximal combination [4].

\section{DATA OBTAINED IN THE PRESENCE OF SALT}

Curves obtained in the presence of salt (constant concentrations of the anions of each respective acid) have a more gradual slope (about -0.5 instead of -1.0 in a logarithmic plot such as that used in fig. 2). The relation between the amounts of acid bound and $\mathrm{pH}$ for these curves is described almost equally well by the modified equations. This is illustrated in figure 3 ; the curve drawn through the experimental points for hydrochloric acid is theoretical, using the value of $K_{\mathrm{A}}{ }^{\prime}$ calculated from the experiment without salt. The equation used to calculate this curve was

$$
\begin{aligned}
\text { Fraction combined } & =\frac{[\mathrm{WHA}]+\left[\mathrm{WH}^{+}\right]+\frac{a_{\mathrm{H}}}{a_{\mathrm{A}}}\left(\left[\mathrm{WA}^{-}\right]-\left[\mathrm{WH}^{+}\right]\right)}{[\mathrm{WHA}]+\left[\mathrm{WH}^{+}\right]+\left[\mathrm{WA}^{-}\right]+\left[\mathrm{W}^{ \pm}\right]} \\
& =\frac{1}{1+\left(\frac{K_{\mathrm{H}}^{\prime}}{a_{\mathrm{H}}}\right)^{1 / 2}\left[\frac{a_{\mathrm{A}}^{1 / 2}+\left(K_{\mathrm{A}}^{\prime}\right)^{1 / 2}}{a_{\mathrm{A}}^{1 / 2}+K_{\mathrm{A}}^{1 / 2}}\right]} \\
& +\frac{\frac{a_{\mathrm{H}}}{a_{\mathrm{A}}}\left[\left(\frac{a_{\mathrm{A}}}{K_{\mathrm{A}}^{\prime}}\right)^{3 / 2}-\left(\frac{a_{\mathrm{H}}}{K_{\mathrm{H}}}\right)^{1 / 2}\right]}{\left(\frac{a_{\mathrm{H}}}{K_{\mathrm{H}}}\right)^{3 / 2}\left[\left(\frac{a_{\mathrm{A}}}{K_{\mathrm{A}}}\right)^{1 / 2}+1\right]+\left(\frac{a_{\mathrm{A}}}{K_{\mathrm{A}}^{\prime}}\right)^{1 / 2}+1}
\end{aligned}
$$


This equation differs from eq 3 only by the presence of a correction term which affects appreciably only the upper part of the curve. This low-affinity form (eq 3), rather than the high-affinity form, is required because when salt is present the amounts of acid bound should be almost wholly given by the sum of the terms [WHA] and $\left[\mathrm{WH}^{+}\right]$. Even though $\left[\mathrm{WA}^{-}\right]$is larger than $\left[\mathrm{WH}^{+}\right]$, the resulting negative charge on the fibers should be neutralized almost entirely by cations other than hydrogen ions - that is, salt as well as acid is combined. The small correction term is inserted to account for the part of this neutralization brought about by adsorption of hydrogen ions. If the high-affinity form were used, the quantity calculated would be the sum of acid plus salt combined.

The variation with $\mathrm{pH}$ of the amounts combined in the case of the other two acids (fig. 3) is also well described by eq 5 , but the positions with respect to $\mathrm{pH}$ of the predicted curves differ appreciably from those required by the data. This discrepancy is illustrated by the curve

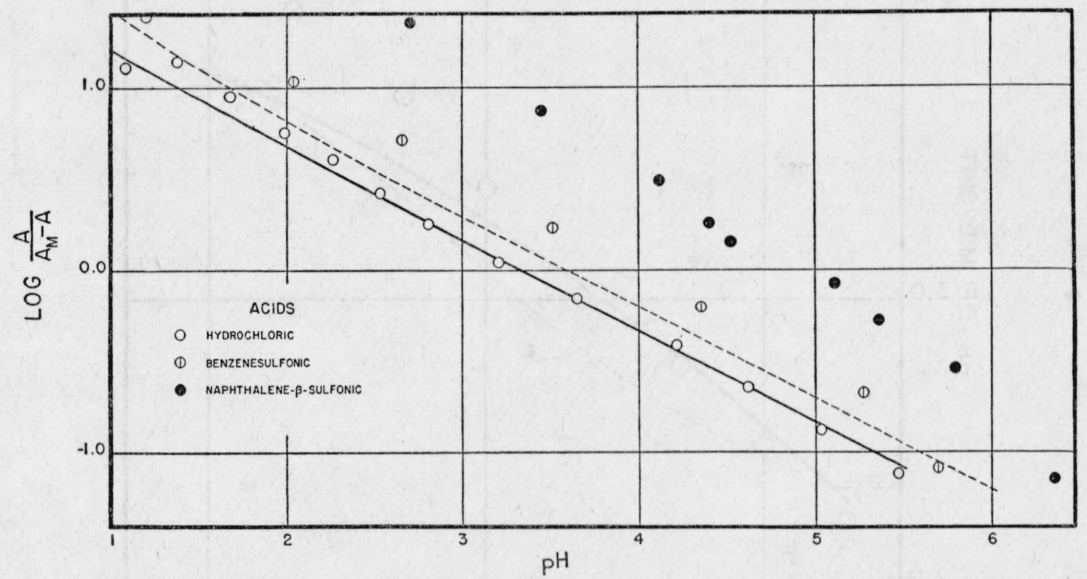

FIGURE 3.-The amounts of three different acids combined by wool as a function of $\mathrm{pH}$, in the presence of a constant concentration $(0.1 \mathrm{M})$ of their anions.

The solid line is theoretical (eq 5) and has been calculated by using the value of $K_{\mathrm{A}^{\prime}}$ for chloride ion given by eq $4^{\prime}$. The broken line was calculated with the value of $K_{\mathbf{A}^{\prime}}^{\prime}$ for benzenesulfonate.

given for benzenesulfonic acid (the broken line), calculated by using the value of $K_{\mathrm{A}}{ }^{\prime}$ given by the experiments with this acid without salt. Such a discrepancy is inherent in the use of eq 5 with anions of high affinity, because this equation cannot represent curves with midpoints at $\mathrm{pH}$ values above 4.2 , the value of $\mathrm{pK}_{\mathrm{H}}{ }^{\prime}$; thus the equation tends to compress the wide range of midpoints observed experimentally into the $\mathrm{pH}$ range below this value. The high-affinity form, eq 4, despite its obvious inapplicability to experiments with salt, is more successful in predicting the large displacements between the upper parts of the curves obtained with different acids, even in the presence of salt [6]. This may signify that there is a greater inherent probability of neutralizing a negative charge on a fiber with a hydrogen ion than with a sodium or potassium ion. Should this be true, the calculation of accurate values of $K_{\mathrm{A}}{ }^{\prime}$ under the more complicated conditions represented in the experiments with salt requires accurate measurements of 
the combination of acid plus salt, to which the simple assumptions underlying eq 4 can be applied. It has been determined experimentally that appreciable amounts of salt are combined. The amounts, however, appear to be smaller than the difference in uptake predicted by eq 4 and 5 .

Since it has been shown previously that the equations without the fractional exponent are of the right form to describe the nature of the dependence of the position of the hydrochloric acid titration curves on the concentration of added salt, it is necessary to show that eq 5 can be used to describe those relations quantitatively, or at least equally well. The extent to which this may be done is shown in figure 4 , in which the $\mathrm{pH}$ of the midpoint of the titration curves

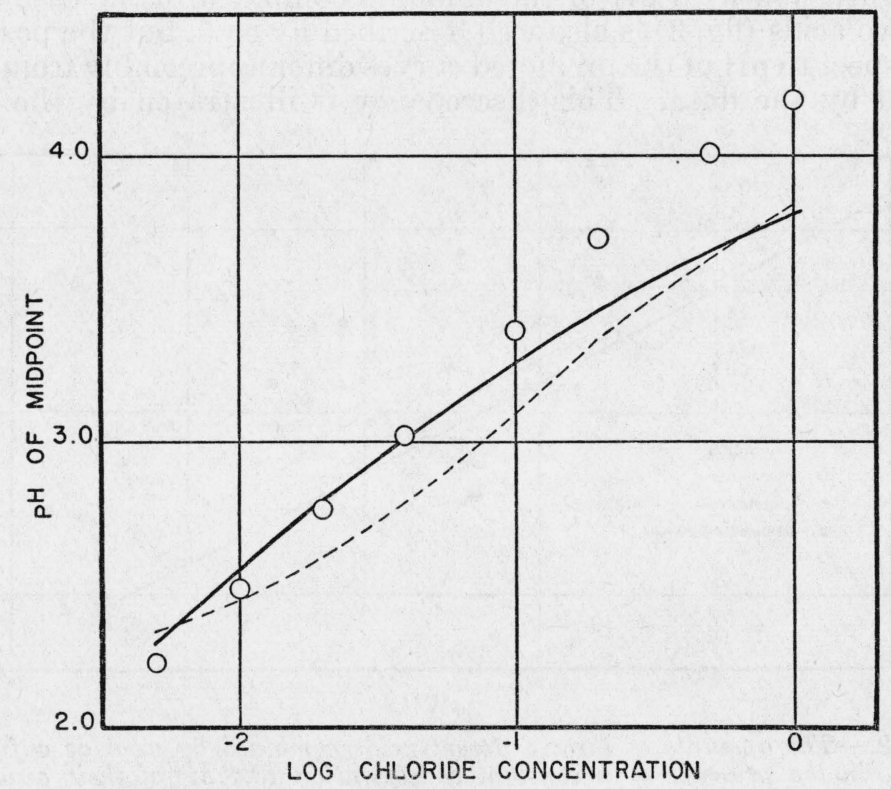

FigURE 4.-The dependence of the $\mathrm{pH}$ of half-maximal combination with hydrochloric acid on the level at which the chloride concentration is held constant.

The solid line represents eq 5 . The broken line was calculated from the equations previously used [3].

obtained with hydrochloric acid is plotted as a function of the total chloride-ion concentration. The solid curve represents the relation between these variables predicted by eq 5 with a ratio of $\left(K_{\mathrm{H}} / K_{\mathrm{H}^{\prime}}\right)^{3 / 2}$ of 100 , and the value of $K_{\mathrm{A}}^{\prime}$ used in figure 2 . The agreement with the experimental data is satisfactorily close for solutions of-less than $0.1 M$ concentration. The discrepancy at higher concentrations is probably not important in view of the consistent neglect in this analysis of all questions of the relation between thermodynamic activity and concentration in both the wool and the aqueous phases. ${ }^{4}$ High values of the ratio $\left(K_{\mathrm{H}} / K_{\mathrm{H}}{ }^{\prime}\right)^{3 / 2}$ give a better approximation to the data than do low values.

\footnotetext{
- The discrepancy at high concentrations could be greatly reduced by adopting a smaller value for $\mathrm{K}_{\mathrm{H}}$ '. Consistent use of a smaller value of $K_{\mathrm{H}^{\prime}}$ would change the numerical values of $K_{\mathrm{A}}^{\prime}$ but would have little effect on theoretical functions other than the one considered here.
} 
The relationship predicted by an exact analysis in terms of the earlier equations [3] is shown by the broken line; the actual experimental values are fitted less well by these earlier equations than by eq 5 . Since the simple assumptions underlying the present analysis are more likely to be applicable to the most dilute solutions, the fact that eq 5 yields the correct slope as well as the best approximation to the absolute experimental values in the most dilute range is definitely in its favor. In every particular in which they have been tested, therefore, relationships based on eq 3 and 4 of this paper have proved equally useful or superior to those based on the older forms. In experiments with mixtures, the new modifications are of still wider general utility [4].

\section{REFERENCES}

[1] W. Kern, Z. physik. Chem. [A] 189, 249 (1938); Biochem. Z. 301, 338 (1939).

[2] J. Steinhardt, Ann. N. Y. Acad. Sci. 41, 287 (1941).

[3] J. Steinhardt and M. Harris, J. Research NBS 24, 335 (1940) RP1286; Textile Research 10, 181 (1940); Am. Dyestuff Reptr. 29, 103 (1940).

[4] J. Steinhardt and M. Harris, Proc. Am. Soc. Biological Chemists XXXV, J. Biol. Chem. 140, cxxiv (1941). A more complete account is in preparation.

[5] J. Steinhardt, C. H. Fugitt, and M. Harris, J. Research NBS 25, 519 (1940) RP1343; Textile Research 11, 72 (1940); Am. Dyestuff Reptr. 29, 607 (1940).

[6] J. Steinhardt, C. H. Fugitt, and M. Harris, J. Research NBS, 26, 293 (1941) RP1377; Textile Research 11, 259 (1941); Am. Dyestuff Reptr. 30, 223 (1941).

[7] J. Steinhardt, C. H. Fugitt, and M. Harris, J. Re earch NBS 28, 201 (1942) RP1453.

Washington, November 7, 1941. 